\title{
Digital Transformation in Compound Animal Feed of Russian Federation: Situation Analysis and Promising Solutions
}

\author{
Vasilenko V.N.* \\ Voronezh State University of Engineering Technology \\ Voronezh, Russia \\ e-mail: vvn_1977@mail.ru \\ Frolova L.N. \\ Voronezh State University of Engineering Technology \\ Voronezh, Russia
}

\author{
Popov A.P. \\ Voronezh State University of Engineering Technology \\ Voronezh, Russia
}

Mikhailova N.A.

Voronezh State University of Engineering Technology

Voronezh, Russia

\author{
Dragan I.V. \\ Voronezh State University of Engineering Technology \\ Voronezh, Russia
}

\begin{abstract}
Russia has a significant reserve to improve the efficiency of agricultural production (by 3-5 times) and the potential to grow the turnover of the industry through the introduction of digital technologies and modern digital platforms for management at various levels agricultural production. Through digital transformation in the feed industry, the following challenges are to be addressed in a comprehensive way: improving productivity; Increased export revenue Maximizing the value of the industry's businesses Increased economic growth in industries (spheres); Creating an effective sales chain from manufacturer to consumer; Integration into related sectors of the digital economy; increasing the attractiveness of work in agriculture and increasing the incomes of agricultural producers. Digital technologies will in the near future become an integral part of agricultural culture, ranging from planting planning and automation of watering and digital crop modelling to the calculation of feed for farm animals, birds and fish. In the course of the research, the task was set to create a system of automated design of functional feeds: from the available resources of raw materials to make formulations of functional feeds that meet the specified requirements for their nutritional value and chemical composition. Based on the systems of automated design of the processes of production of functional feeds, we have a number of developed mathematical models, which allow realistic prediction of changes occurring in raw materials and finished Product. The automated feed design systems we develop and the mathematical modelling behind them can contribute to the digital transformation of the feed industry, as well as to the replacement of the feed industry domestic software.
\end{abstract}

Keywords - agricultural production, animal feed, digital technologies, digital economy.

\section{INTRODUCTION}

Traditional resources to improve agricultural efficiency have almost dried up. However, Russia has a significant reserve to increase the efficiency of agricultural production by 3-5 times and the potential to grow the turnover of the industry through the introduction of digital technologies and modern digital platforms for management at various levels agricultural production. Many of the decisions made in both enterprise design and feed production are digitalized. However, the opportunities offered by digital technologies are currently only partially used [1-3]. The insufficient level of digitalization of the industry is also indicated by the fact that about 4.7 million people are employed in agriculture, while only one information technology specialist is employed per 1,000 people. The transformation of the agro-industrial complex of the Russian Federation involves the digitalization of all areas of agricultural production: crop production, animal husbandry, fishing, poultry farming, breeding and genetics, the greenhouse industry, and others. The expected results (targets) of the transformation of agriculture are: the growth of the contribution to the economy in 2024 to 5.9 trillion rubles; Increase in export revenue of enterprises to 45 billion dollars; improving management.

Through the digital transformation of agricultural sectors (spheres), a complex solution of the following tasks is expected: increasing labor productivity; increasing export revenue; maximizing the value of industry enterprises; increasing the economic growth rates of industries (spheres); creating an effective sales chain from producer to consumer; integrating into related sectors of the digital economy; increasing the attractiveness of working in agriculture and increasing the incomes of agricultural producers.

The digital transformation of agriculture involves systemic changes: in the means of agricultural production; Storage and 
processing infrastructure oversight and control processes, as well as educational processes.

\section{LITERATURE REVIEW}

A study by the Russian Union of Industrialists and Entrepreneurs reports that by 2020 the number of devices connected to the Internet will reach 1.9 million. By 2021, the volume of the Russian artificial intelligence market in the industry will amount to $\$ 380$ million. Experts note that machine learning technologies are used most in discrete manufacturing. It includes, among other things, food engineering. This area includes $44 \%$ of the projects considered in the study in the field of artificial intelligence. Another $23 \%$ are at an early stage of development. "These are mainly University research papers that explore the use of artificial intelligence methods in areas that are new to the industrial sector", the study says.

However, attempts are being made to use artificial intelligence in the Russian food industry as well.

Since 2018, employees of the information technology Department have been conducting research in the field of machine learning in the agricultural and industrial company EFCO. Python and specialized machine learning libraries such as NumPy And Pandas are used as platforms. The technology is used for data classification tasks "with a teacher" using neural network algorithms. Now these solutions are being tested in the format of pilot projects by the information technology service in terms of classification of applications and their subsequent distribution, as well as by the financial Department for generating management reports. Machine learning and artificial intelligence technologies allow EFCO to work more efficiently and use less human resources for standard routine work. In the free time, employees solve more complex intellectual tasks.

So far, not many industrial companies in Russia use artificial intelligence in their business processes. However, the advantages of artificial intelligence encourage its implementation in various areas of activity of the largest Russian organizations in various industries of the industrial sector. Judging by what technologies are already being used, the prospects for the development of artificial intelligence in the domestic industry are wide and promising [4-6].

The agricultural sector can become a key one for the Russian investment market. $4.5 \%$ of national domestic production, the position of the largest grain exporter, $10 \%$ of the global Fund of arable land, all these are prerequisites for the demand for high technologies in the agricultural sector is growing from year to year, and the end of demand is not yet visible - which means that there will be investors even for the most daring projects.

Skolkovo resident, Aqual makes automated systems for fish farms. The world's aquaculture market, according to the company, will reach 200 billion dollars by 2020. The automation market is up to $\$ 2$ billion. The Russian automation market will be $\$ 200$ million, and by 2020 the company plans to occupy $5 \%$. The main problems in the fishing industry are the high costs of growing and dying the fish herd. Aqual's software and hardware system avoids these problems. Automation reduces lab costs by $40 \%$, and the manufacturer can also spend a third less money for staff and a quarter less money for fish feed. In addition, the accident rate of such production is almost completely reduced.

This solution allows controlling the rate of production and growth of fish depending on the demand in retail. It is done by automatically regulating the basic parameters of the fish farm: the chemical composition of the water, its temperature, saturation oxygen and nitrogen and so on. Thanks to the "internet of things" the farm optimizes its resources without expending excess food for unclaimed fish on the market, as well as ensuring constant and uniform loading of personnel depending on production tasks. In 2017, the technology was implemented at a pilot project in the suburbs, the energy efficiency of the "smart fish farm" was two to three times higher than usual, the cost of production decreased by $20-30 \%$.

At the same time, the processing of agricultural products requires strict quality control and compliance with sanitary standards. Previously, additional staff had been hired to monitor the workers. Now people-controllers at a number of sites are not needed: the industry is rapidly automating, and machines themselves check the work of people without the help of supervisors

The Directive system is gradually learning to distinguish and evaluate different work. Washing our hands and skipping through the turnstiles are just the first steps. Another system, Etalon, also works through video cameras, but evaluates products rather than people's work. In the process of setting up the system in the enterprise video from a particular part of the production, for example, packaging, through a convenient interface is evaluated by a technologist who notes the level of quality of the product. Implementation of such systems usually takes several months: this is how long it takes to train on the spot and adjusts the work of artificial intelligence, explains the expert.

\section{RESULTS AND DISCUSSION}

In the course of the research, the task was set to create a system of automated design of functional feeds for different types of animals and fish: from the available resources of raw materials to make formulations of functional feed, meet the requirements for their nutritional value and chemical composition (Figure 1).

The nutritional value of feed and the volume of the batch, the nutrient of raw materials and its quantity and the norms of the introduction of raw materials in feed are restrictions. If the solution exists, it is usually not the only one, but there is an infinite number of them (indeed, by changing the percentage of input of a component by a hundredth of a percent, we will get another recipe). The problem may not have a solution; this means that the raw materials are not in sufficient nutritional value or are not available in sufficient quantities. So, if there is a solution, then the following requirement is formulated as follows: from the entire infinite set of possible solutions (possible variants of the recipe), each of which meets the requirements for nutritional value, choose the one that most suits the user for some characteristics (criteria) [7]. 
The actual calculation of the recipe is an iterative procedure in which the user forms the raw data, receives the solution, analyzes it, corrects the original data and gets a new solution, etc. until the proposed option will not satisfy the user. Requirements for the quality of feed products are set by the relevant regulatory and technical documents (standards, technical conditions, etc.). For specific recipes, it is usually stated that quality metrics should be "no more" or "no less" than certain numerical values. The values of specific product quality calculations, equal to those of indirect measurements, are based on the appropriate quality and mass of the different types of raw materials included in the recipe and the production mass. In the production of products, the values of the mass of different raw materials and their quality indicators are determined by the use of specific weight devices and methods of quantitative chemical analysis. However, both are characterized by measurement errors reflected in the relevant standards, which leads to errors in the evaluation of calculated product quality indicators. It is important for product producers to know the numerical values of calculated quality indicators and the expected margins of error in their assessment at the pre-production stages.

The information and educational program "Ecocorm" is an application for Microsoft Windows 10 and higher operating systems and provides an intuitive graphical user interface (figure 2).

Optimization and comprehensive analysis of rations feed and premixes.

Basic algorithmic positions.

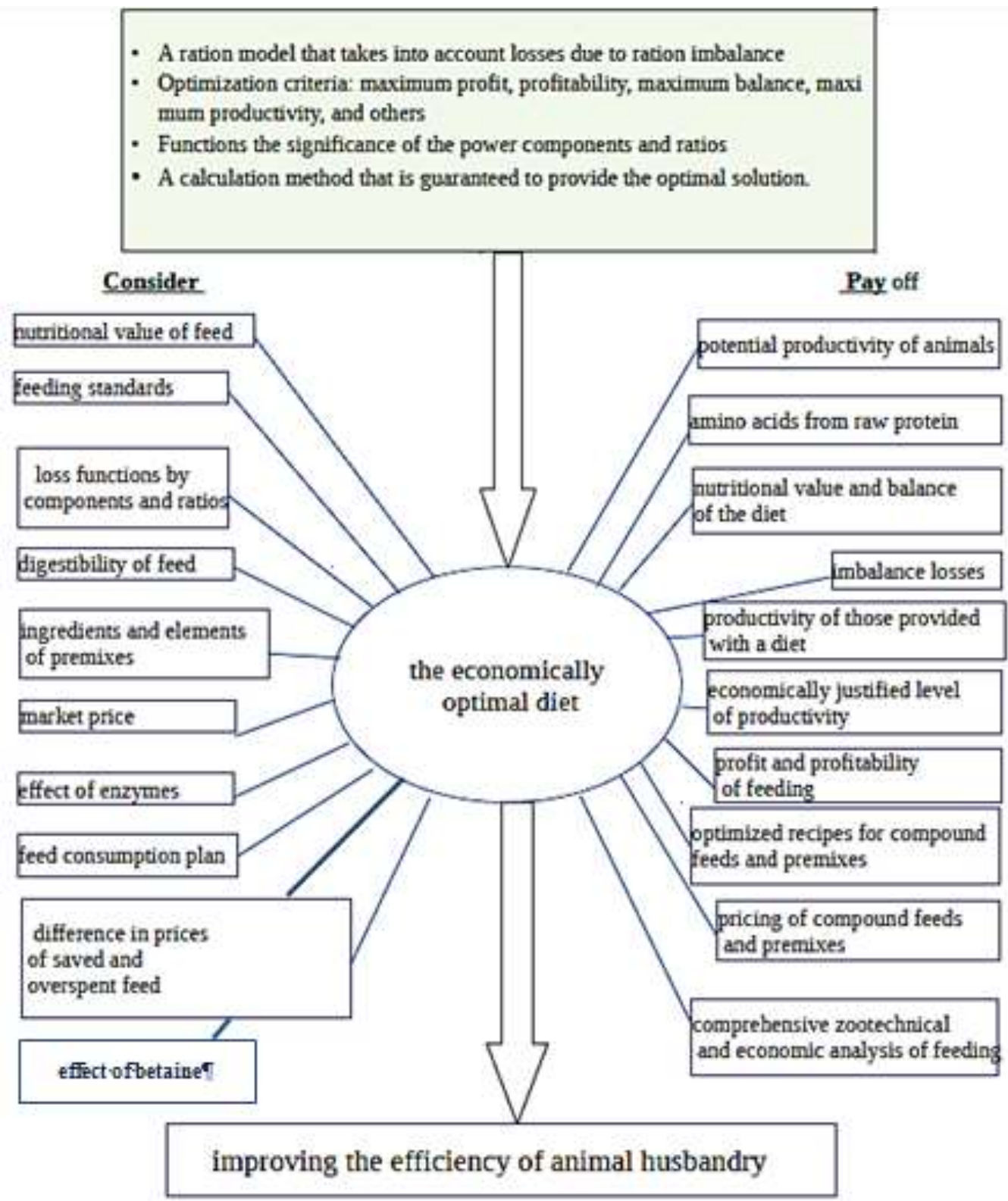

Fig. 1. Optimize the feed formulation process 


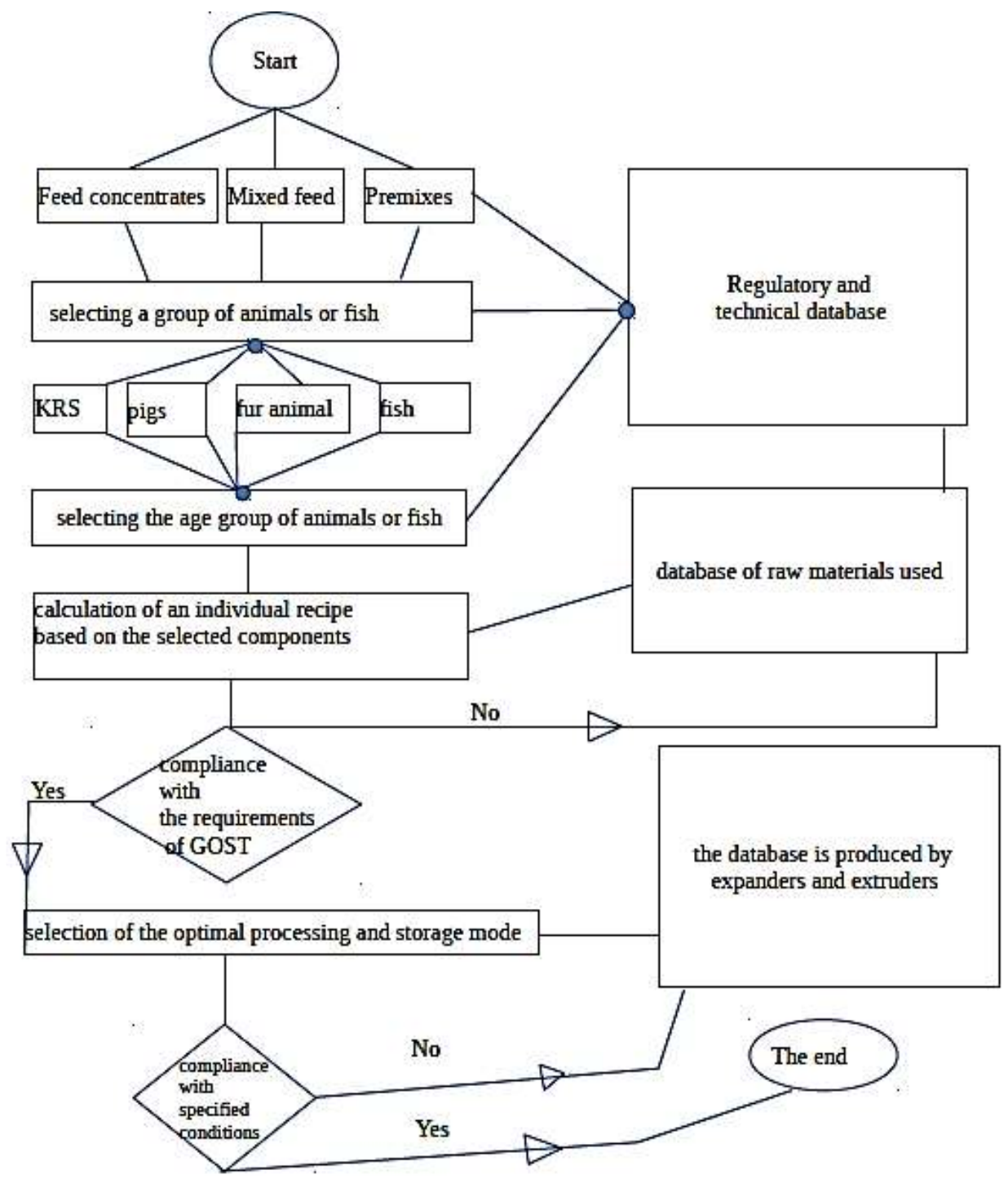

Fig. 2. Block diagram of the program «Ekokorm»

The calculations are presented in the form of a convenient illustrated wizard that allows flexible and convenient set of the input data for calculations. Support for tabs in the main window allows displaying the results of several different calculations at the same time. The program includes features for quick navigation between sections of the report on the results of the calculations, and a flexible filter system that allows varying the detail of the report; leave the report only relevant data (figure 3).

For products made according to a calculated recipe consisting of different types of raw materials, the value of a particular chemical quality indicator is determined by the expression:

$$
C=\sum_{j=1}^{n} M_{j} C_{j} / \sum_{j=1}^{n} M_{j}
$$

where $C$ - is a massive proportion of the chemical component (quality indicator) in products; $C_{\mathrm{j}}-$ is a massive part of the component in the j-type raw materials; $M_{\mathrm{j}}$ - is a massive share of the $j$-st type of raw materials in the products; $\sum_{j=1}^{n} M_{j}=M_{\Sigma}-$ the total mass of products produced; $M_{\mathrm{j}} C_{\mathrm{j}}=m_{\mathrm{j}}-$ is a mass of a component in the $\mathrm{j}$-as-raw; $\sum_{j=1}^{n} M_{j} C_{j}=m_{\Sigma}-$ the total mass of the chemical component in the feed.

As it can be seen from the expression (1), the calculation is based on an equation based on the values of $M_{\mathrm{j}}$ and $C_{\mathrm{j}}$, which measure directly. If the measurements of these values are made once, which is done in the production of feed products, the error of the result of the indirect measurement of the $\Delta C$ is determined by the errors of measurements $\Delta M_{\mathrm{j}}, \Delta C_{\mathrm{j}}$, and errors that occur when performing mathematical 
transformations of the function $\mathrm{C}$, by decomposing it into a the standards for metrological parameters of dispensers.

Taylor series. Limit values of errors $\Delta M_{\mathrm{j}}$ and $\Delta C_{\mathrm{j}}$ are given in

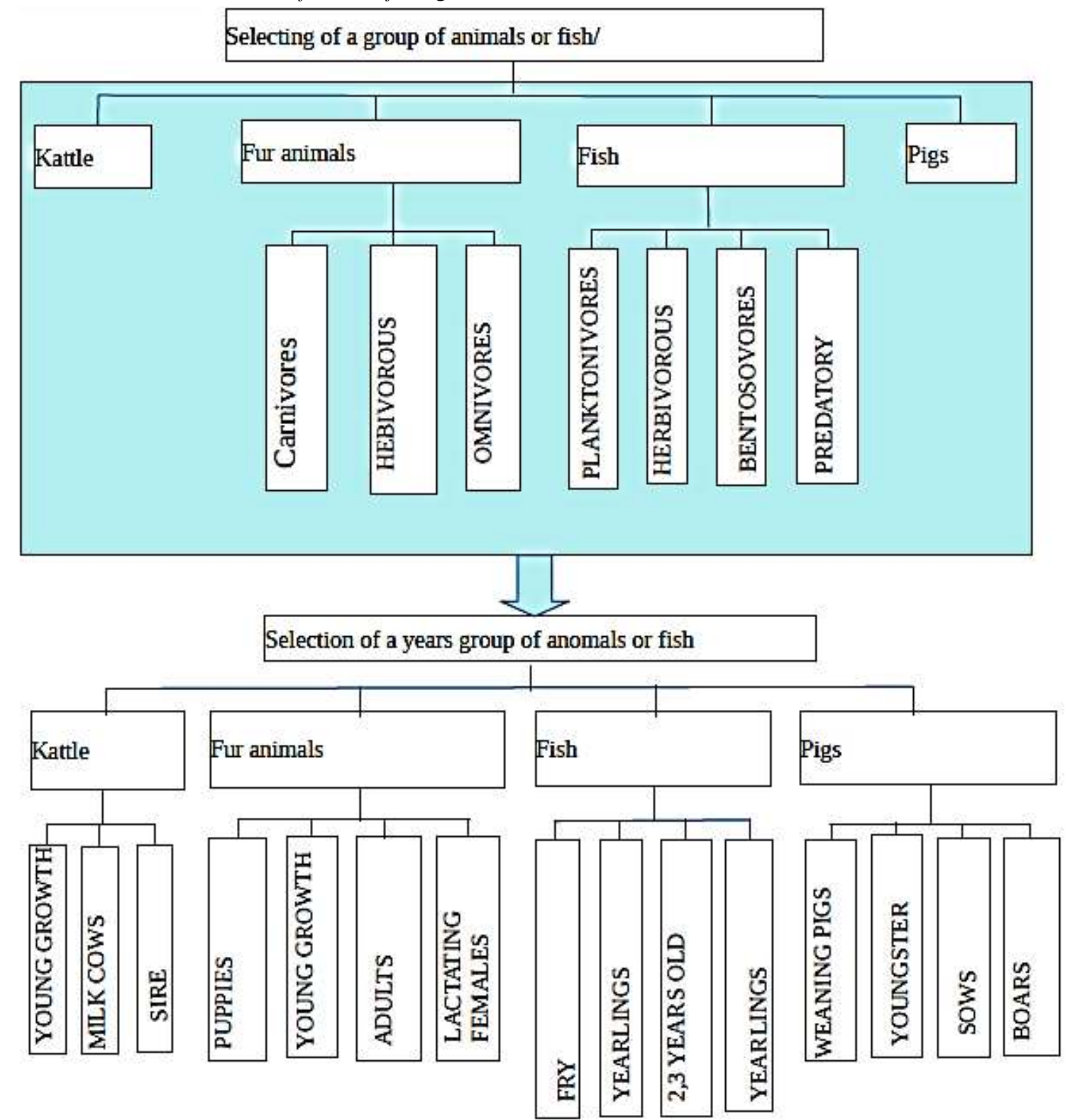

Fig. 3. Block diagram of the subsystem of group selection program "Ekokorm»

Under certain conditions the square of the average square error $\Delta C^{2}$ is equal to the sum of the squares of the products of partial derivatives of functions $\mathrm{C}$ for each argument on the error of the corresponding arguments (2):

$$
\Delta C^{2}=\sum_{j=1}^{n}\left(\frac{\partial C}{\partial M_{j}}\right)^{2}\left(\Delta M_{j}\right)^{2}+\sum_{j=1}^{n}\left(\frac{\partial C}{\partial C_{j}}\right)^{2}\left(\Delta C_{j}\right)
$$

Usually, not all types of raw materials introduced into products contain a chemical that determines its quality index. If $K-$ is the number of raw materials containing the required chemical, then $K<n$. taking into account the latter, the average square error of the $\Delta C$ function, expressed as a percentage, is determined by the expression (3):

$$
\Delta C=\left(\frac{100}{M_{\Sigma}}\right)\left\{\frac{1}{M_{\Sigma}^{2}}\left[\sum_{j=1}^{k}\left(M_{\Sigma} C_{j}-m_{\Sigma}\right)^{2} \Delta M_{j}^{2}+\sum_{j=k+1}^{n}\left(m_{\Sigma} \Delta M_{j}\right)^{2}\right]+\sum_{j=1}^{k}\left(\Delta m_{j}\right)^{2}\right\}^{0.5}
$$

where $\Delta m_{j}=M_{j} \Delta C_{j}-$ is the absolute error in estimating the chemical content in the $\mathrm{j}$ - th type of raw material that determines its quality index.

Substituting the limit values of the errors $\Delta M_{j}$ and $\Delta C_{j}$ in the last expression, we can estimate the limit value of the mean square error of the function $\Delta C$. 
The basis of our computer-aided design systems for the production of functional feed is based on a number of developed mathematical models that allow adequate prediction of changes occurring in the raw material and the finished product [7-9].

\section{CONCLUSIONS}

Often, companies spend huge amounts of money to maintain outdated technologies that have not been profitable for a long time and do not meet the requirements of the digital market. It is too expensive to keep outdated technologies in working order, and it is even more expensive to upgrade them. In addition, they require more than one person to serve them. It is much easier to spend on the latest technologies and expand the pool of clients than to slowly go broke trying to maintain an unprofitable business. Digital technologies will become an integral part of agricultural culture in the near future, from crop planning, irrigation automation, and digital crop modeling to calculating feed for farm animals, birds, and fish.

Our computer-aided design systems for feed production processes and the mathematical modeling that underlies them can contribute to the digital transformation of the feed industry, as well as to the replacement of foreign feed.

\section{References}

[1] A.A. Shevtsov, A.V. Drannikov, A.A. Derkanosova, A.S. Muravev et al., "Experimental and analytical study of the beet pulp drying process by overheated steam in active hydrodynamic conditions", J. of Engineer. and Appl. Sci., vol. 12, no. 1, pp. 5754-5760, 2017.

[2] A.A. Shevtsov, V.N. Vasilenko, A.V. Evdokimov, "Control algorithm of the thermal applying drying plant for thermolabile materials", Avtomatiz. i Sovrem. Tekhnol., vol. 7, pp. 26-28, 2004.

[3] I.V. Novikova, I.A. Yuritsyn, A.S. Muravev, "Effects of aeration intensity on the growth and activity of Brettanomyces bruxellensis", Proc. of univer. Appl. Chem. and Biotechnol., vol. 9, no. 1(28), pp. 102-108, 2019.

[4] V.N. Vasilenko, L.N. Frolova, N.A. Mikhailova, I.V. Dragan, D.A. Tarkaeva, "Resource-Saving Press for Oil Extrusion from Plant Sources”, Russ. Engineer. Res. vol. 39, no. 7, pp. 575-576, 2019.

[5] A.N. Ostrikov, A.S. Rudometkin, V.N. Vasilenko, "Automatic control and pressure adjustment in prematrix zone of extruders", Avtomatiz. i Sovrem. Tekhnol., vol. 8, pp. 14-18, 2002.

[6] V.V. Rusanov, V.I. Perov, M.A. Samoilov, "Automation of public catering enterprises using modern digital technologies: Arduino IDE, OPC Modbus and Master Scada programs", Proc. of the Voronezh State Univer. of Engineer. Technol., vol. 80, no. 2, pp. 38-44, 2018.

[7] G.V. Alekseev, O.I. Aksenova, A.A. Derkanosova, "Optimization of feed for unproductive animals with the help of mathematical modeling", Proc. of the Voronezh State Univer. of Engineer. Technol., no. 1, pp. 28-35, 2015.

[8] A.L. Maytakov, A.M. Popov, N.T. Vetrova, L.N. Beryazeva, M.A. Zverikova, "Modeling of manufacturing technologies for multicomponent granulated products", Proc. of the Voronezh State Univer. of Engineer. Technol., vol. 80, no. 4, pp. 63-68, 2018.

[9] A.N. Ostrikov, A.A. Shevtsov, L.I. Lytkina, D.V. Shirikov, M.K. Kurmanakhynova, "Fish smoking process modeling", Int. J. of Appl. Engineer. Res., vol. 10, no. 21, pp. 42682-42687, 2015. 